DOI: 10.12731/2658-4034-2020-3-48-54

\title{
ЭЛЕКТРОННЫЙ ТЕСТОВЫЙ МЕТОД КОНТРОЛЯ НА ЭТАПЕ ФРОНТАЛЬНОГО ОПРОСА НА УРОКАХ ИНФОРМАТИКИ У УЧАЩИХСЯ СРЕДНЕЙ ШКОЛЕ
}

\section{Столярова И.В.}

Балтийского Федерального университет имени Иммануила Канта, г. Калининград, Российская Федерация

В статье рассматривается проблема современного контроля знаний в образовательных учреждениях. Представлены виды контроля, их недостатки и возможности. Особое внимание уделено фронтальному опросу, который осуществляется при помощи компьютерного тестирования.

Ключевые слова: интерактивные системь; контроль знаний; электронное тестирование; тест; фронтальный опрос; компьютерное тестирование.

\section{ELECTRONIC TEST METHOD OF MONITORING AT THE STAGE OF THE FRONT SURVEY AT INFORMATICS LESSONS AT STUDENTS OF SECONDARY SCHOOL}

\author{
Stolyarova I.V. \\ Immanuel Kant Baltic Federal University, \\ Kaliningrad, Russian Federation
}

This article discusses the problem of modern knowledge control in educational institutions. The types of control, their disadvantages and capabilities are presented. Particular attention is paid to the frontal interrogation, which is carried out using computer testing.

Keywords: interactive systems; knowledge control; electronic testing; test; frontal interrogation; computer testing. 
За последние несколько лет в нашей стране произошло коренное изменение роли и места персональных компьютеров и информационных технологий в образовательной среде. Обучение с применением интерактивных систем становится более качественным, интересным и продуктивным. Данные средства помогают усилить мотивацию учащихся к стремлению освоения новых знаний. В современных школах появились интерактивные средства обучения, не только для разработки интересного урока, но также для контроля знаний и отслеживания успеваемости [1].

С развитием информационных технологий процесс контроля и качества знаний стал намного проще, удобнее и быстрее. Система проверки в образовательных учреждениях должна отойти от традиционной формы оценивания и вместо бумажного тестирования переходить на компьютерное, тогда процесс оценивания станет мгновенным и качественным, что повлечет за собой гибкость управления учебным процессом.

В современных школах еще пока не так активно применяется данная методика, так как многие педагоги придерживаются старых приемов, например, устного опроса или письменного тестирования, и не могут в полной мере ощутить, или понять гибкость и удобность электронного тестирования [1].

Использование компьютерного тестирования, например, на этапе фронтального опроса позволяет автоматизировать процесс проверки работ учащихся и сразу же вывести результат - оценку. Ученики проходят данное тестирование с удовольствием, без лишних вопросов и высказываний негодования, даже если полученная оценка “неудовлетворительно”, то обучающиеся горят желанием как можно скорее ее исправить.

Устный опрос, осуществляется на каждом уроке, и оценка знаний отвечающих учеников может быть не обязательна. Главное в контроле - это выявление проблемных мест и своевременное их устранение. Устная проверка считается эффективной если она направлена на нахождение осмысленности воспринимаемых знаний и осознанности их использования, с учетом того что она стимулирует самостоятель- 
ность и творческую активность учеников. Но в большинстве случаев не приносит положительного результата, так как при устном опросе не хватает времени, выделенного на уроки, для того чтобы опросить весь класс.

Результатом контроля деятельности обучающихся выражается в отметках, полученных учащимися в результате этой деятельности. В современных российских школах традиционно применяется пятибалльная система оценивания. Отметка выставляется в зависимости от собственных представлений педагога о том, что для него есть средний уровень знаний, причем для каждого учителя он может быть разный не только для класса, но и индивидуально к разным ученикам [5]. Современная пятибалльная шкала фактически сводится к трехуровневой: 5 (отлично) - выше среднего; 4 (хорошо) - средний уровень; 3 (удовлетворительно) - ниже среднего.

Отметку “2”, многие преподаватели,по их собственному признанию стараются не ставить. Если же она стоит, то в основном “за поведение”, что в реальности не является оценкой реальных знаний, а лишь выступает в роли карательной меры или же как одним из способов запугивания учеников. При этом отметка “1”, вообще не используется, так как многие педагоги подвергаются выговору или критике со стороны администрации школы, а в электронном журнале она вообще не имеет точного веса. Есть еще один немало важный факт, того что, некоторые педагоги, отказываются ставить отметку “5”, по причине того, что на "5" знают только преподаватели, а у учеников остается только “4” и “3” и в крайних случаях “2”. Но данный случай попадается довольно редко, и в основном при устном опросе. Исходя из этого, одним из плюсов электронного тестирования, является то что оценка выставляется по заранее составленными критериями, и является субъективной, не принимая во внимания личностные качества или неприязни ученика.

Текущий контроль может быть реализован в рамках фронтального опроса с целью подведения итогов и плавного перехода к новому разделу. Суть проверки результатов обучения состоит в том, чтобы выявить уровень освоенности изученного материала, который 
должен соответствовать образовательному стандарту (ФГОС ООО) по данной программе. Нет точного места времени проведения контроля, но многие преподаватели отдают предпочтение проведению контроля на этапе фронтального опроса, так как у педагогов появляется возможность не только проверить знания учащихся по прошлому материалу, но и внести коррективы в изучение следующей темы, опираясь на проблемные или сильные стороны.

Тест, включающий в себя разработанный комплекс заданий, по которым можно качественно оценить усвоение знаний, умений и навыков, является инструментом, который позволяет реально оценить качество усвоения пройденного материала.

Если рассматривать тестирование как метод педагогического контроля, нужно разобраться в понятиях “тест” и “тестовое задание”, многие преподаватели считают, что это одинаковые понятия, но на самом деле они являются разными педагогическими разработками [2]. Тест всегда состоит из комплекса тестовых заданий, но не каждый набор тестовых заданий может быть тестом.

Анализ методической литературы по исследуемой тематике позволяет трактовать понятия “тест” и “тестовые задания” в следующей формулировке:

Tecm - это система заданий возрастающей трудности, которая позволяет эффективно выявить уровень и качественно оценить структуру подготовленности учащихся.

Тестовое задание - это задание, к которому, помимо содержания, предъявлены следующие требования: одинаковость инструкции по его выполнению для всех испытуемых, адекватность инструкции по форме и содержанию задания, краткость, формулирование задания в виде логического высказывания, правильность расположения элементов задания, наличие определенного места для ответов, одинаковость правил оценки ответов в рамках принятой формы.

Иначе говоря, mесm - это заранее подготовленный системный комплекс заданий, прошедший предварительную экспертную проверку, для того чтобы выявить уровень освоения изученного материала [4]. 
Электронные тесты объективного контроля обладают следующими признаками:

- однозначность - указанные ответы и вопросы нельзя переделать или как интерпретировать по-своему;

- мгновенный результат получения результата о правильности или ошибочности действий учащихся;

- заранее подготовленная и оговоренная система оценивания;

- тщательно продуманный подготовленный комплекс заданий в соответствие разработанными критериями и правилами, которые отвечают требованию ФГОС ООО;

- предварительная проверка, которая проводится с целью исключения возникновения внештатных ситуаций;

- независимость оценивания;

- мгновенное получение оценки;

- опрос всех учащихся;

- возможность количественного учета математико-статистической обработки результатов.

Текущий контроль, как уже было сказано выше, позволяет не только отследить степень освоения учебного материала, но и отследить успешность применяемых методов обучения [3]. Такая форма контроля должна носить систематический характер и быть узконаправленной, то есть включать вопросы и задания, которые связаны с пройденным материалом на прошлом занятии. Это позволяет держать учеников в тонусе, способствует быстрому выявлению и устранению пробелов в пройденном материале.

Фронтально опроса осуществляется в часто в устной форме, но недостаток данной формы в том, что при ее использовании не удается проверить и опросить всех учеников, поэтому рациональнее всего будет реализовать фронтальный опрос посредством тестирования. После его завершения необходимо проанализировать допущенные ошибки и в этом преподавателю помогают графики или диаграммы, которые отображают статистику правильных и неправильных ответов [2]. Каждый ученик имеет право ознакомится со своими ошибками, для того чтобы в дальнейшем проработать или доработать проблемные места. 
Таким образом, использование электронного тестового метода контроля позволяет организовать работу всех учеников и включить их в образовательный процесс, объективно оценить работы учащихся, что до сих пор является большой проблемой педагогической системы.

\section{Список литературы}

1. Алексеева Е.Е. К определению понятия компетентность в цифровизации образования // Известия Балтийской государственной академии рыбопромыслового флота: психолого-педагогические науки. 2019. № 3 (49). С. 78-79.

2. Алексеева Е.Е., Лушников Е.М. Основы теории меркаторских навигационных карт // О морские интеллектуальные технологии. 2019. № 2-2 (44). С. 64-68.

3. Жунусакунова А. Д. Методы контроля и оценки результатов обучения в учебном процессе // Молодой ученый. 2016. №20.1. С. 26-29.

4. Карташова Л.И. Методика обучения информационным технологиям обучающихся основной школы в условиях фундаментализации образования // Л.И. Карташова, И.В. Левченко // Вестник Московского гор. Пед. Ун-та. Серия «Информатика и информатизация образования». 2014. № 2 (28). С. 25-33.

5. Сластенин В.А. Педагогика: учеб. пособие для студентов высших пед. учебных заведений / В.А. Сластенин, И.Ф. Исаев, Е.Н. Шиянов. М.: Академия, 2013. 576 с.

\section{References}

1. Alekseeva E.E. K opredeleniju ponjatija kompetentnost' v cifrovizacii obrazovanija [To the definition of competence in the digitalization of education] // Izvestija Baltijskoj gosudarstvennoj akademii rybopromyslovogo flota: psihologo-pedagogicheskie nauki. 2019. № 3 (49). S. 78-79.

2. Alekseeva E.E., Lushnikov E.M. Osnovy teorii merkatorskih navigacionnyh kart [Fundamentals of the theory of Mercator navigational charts] // O morskie intellektual'nye tehnologii. 2019. № 2-2 (44). S. 64-68. 
3. Zhunusakunova A.D. Methods of control and evaluation of learning outcomes in the educational process // Young scientist. 2016. No. 20.1. S. 26-29.

4. Kartashova L.I. Methods of teaching information technology to students of the primary school in the conditions of fundamentalization of education // L.I. Kartashova, I.V. Levchenko // Bulletin of the Moscow Mountains. Ped. University. Series "Informatics and informatization of education.” 2014. No. 2 (28). S. 25-33.

5. Slastenin V.A. Pedagogy: textbook. manual for students of higher ped. educational institutions / V.A. Slastenin, I.F. Isaev, E.N. Shiyanov. M.: Academy, 2013. 576 p. 